\title{
Reclassification of Methanogenium tationis and Methanogenium liminatans as Methanofollis tationis gen. nov., comb. nov. and Methanofollis liminatans comb. nov. and description of a new strain of Methanofollis liminatans
}

\author{
Gerhard Zellner, ${ }^{1}$ David R. Boone, ${ }^{2}$ Jyoti Keswani, ${ }^{3}$ William B. Whitman, ${ }^{3}$ \\ Carl R. Woese, ${ }^{4}$ Anja Hagelstein, ${ }^{5}$ B. J. Tindall ${ }^{5}$ and Erko Stackebrandt ${ }^{5}$
}

Author for correspondence: Gerhard Zellner. Tel: +4989 3187 2579. Fax: +498931873361. e-mail: zellner@gsf.de

1 Institute of Hydrology, GSF - National Research Center for Environment and Health, Ingolstädter Landstraße 1, D-85764

Neuherberg,

Germany

2 Oregon Graduate Institute of Science and Technology, Portiand, OR 97291-1000, USA

${ }^{3}$ Department of Microbiology, University of Georgia, 527 Biological Sciences Building, Athens, GA 30602-2605, USA

4 Department of Microbiology, University of Illinois, Urbana, IL 61801 USA

5 DSMZ - Deutsche Sammlung von Mikroorganismen und Zellkulturen, D-38124 Braunschweig, Germany

\begin{abstract}
Sequencing of 165 rRNA genes and phylogenetic analysis of Methanogenium tationis DSM $2702^{\top}\left(\mathrm{OCM}^{4} \mathrm{3}^{\top}\right)(\mathrm{T}=$ type strain) and Methanogenium liminatans GKZPZ $^{\top}$ ( = DSM 4140') as well as other members of the family Methanomicrobiaceae revealed that both species belong to a separate line of descent within this family. In addition, a new strain of Methanogenium liminatans, strain BM1 (= DSM 10196), was isolated from a butyratedegrading, fluidized bed reactor and characterized. Cells of both species are mesophilic, highly irregular cocci that use $\mathrm{H}_{2} / \mathrm{CO}_{2}$ and formate for growth and methanogenesis. In addition, Methanogenium liminatans strains GKZPZ and BM1 used 2-propanol/CO 2 , 2-butanol/CO $\mathrm{CO}_{2}$ and cyclopentanol/CO ${ }_{2}$. Both species contained diether and tetraether lipids. The polar lipids comprised aminophosphopentanetetrol derivatives, which appear to be characteristic lipids within the family Methanomicrobiaceae. The pattern of glycolipids, phosphoglycolipids and amino-phosphoglycolipids was consistent with the assignment of these two species to a taxon within the family Methanomicrobiaceae, but also permitted them to be distinguished from other higher taxa within this family. The G+C contents of the DNA of Methanogenium tationis and Methanogenium liminatans were 54 and $60 \mathrm{~mol} \%$ ( $T_{\mathrm{m}}$ and HPLC), respectively. On the basis of the data presented, the transfer of Methanogenium tationis and Methanogenium liminatans to the genus Methanofollis gen. nov. as Methanofollis tationis comb. nov. and Methanofollis liminatans comb. nov., respectively, is proposed, with Methanofollis tationis as the type species.
\end{abstract}

Keywords: Methanogenium tationis, Methanogenium liminatans, Methanofollis gen. nov., lipids, phylogeny

\section{INTRODUCTION}

The DNA of irregularly coccoid methanogens has a wide range of $\mathrm{G}+\mathrm{C}$ contents $(38-61 \mathrm{~mol} \%)$, which

\footnotetext{
Abbreviations: PAS, periodic acid-Schiff; UASB, upflow anaerobic sludge blankẹt.

The GenBank/EMBL accession numbers for the 165 rDNA and rRNA sequences reported in this paper are Y16428, Y16429, AF095266-AF095272.
}

indicates a wide evolutionary diversity among these methanogenic Archaea. However, only a limited number of phenotypic characteristics of irregularly coccoid methanogens are available for taxonomic purposes. In addition to morphology and substrate spectrum, characteristics such as polyamine content (Zellner et al., 1989a; Blotevogel et al., 1991; Boone et al., 1993), cellular lipids (Grant et al., 1985; Zellner et al., 1989a, b, c; Blotevogel et al., 1991; Koga et al., 1993) and whole-cell protein patterns (Maestrojuán et al., 
1990) have been used. The S-layer architecture and the apparent molecular mass of glycoprotein subunits have also been used (Zellner et al., 1989a, c, 1990; Messner \& Sleytr, 1992; Sleytr et al., 1993). Due to the fact that few physiological tests can be used to differentiate taxa within the methanogenic Archaea, other phenotypic characters (e.g. cell wall structure, chemical composition, polyamines) and genotypic characters (e.g. 16S rDNA sequence) must be used to delineate the higher taxonomic ranks. Recent developments in the taxonomy of both Archaea and Bacteria indicate that this combination of phenotypic and genotypic methods is suitable for the delineation of taxa in a system which seeks to base these on the phyletic groupings detected by such data.

Analysis of the sequences of 16S rRNA or its genes revealed a high diversity of irregularly coccoid methanogenic strains, with some deeply rooted lines of descent in phylogenetic trees (Zellner et al., 1989a; Rouvière et al., 1992; Boone et al., 1993). As a consequence, several coccoid methanogens were reclassified on the basis of DNA-DNA hybridization studies and/or 16S rDNA sequence analysis (Xun et al., 1989; Zellner et al., 1989c; Maestrojuán et al., 1990; Boone et al., 1993). This resulted in the description of the five current genera of hydrogenotrophic, irregularly coccoid methanogens of the order Methanomicrobiales: Methanogenium, Methanoculleus, Methanolacinia, Methanoplanus and Methanocorpusculum.

Recently, the reclassification of Methanogenium tationis (Zabel et al., 1984) as Methanofollis tationis was suggested (Boone et al., 1993) but not formally proposed. In this paper, the transfer of Methanogenium tationis and Methanogenium liminatans as Methanofollis tationis gen. nov., comb. nov. and Methanofollis liminatans comb. nov. is proposed on the basis of $16 \mathrm{~S}$ rDNA sequencing and chemotaxonomic and physiological data. In addition, the isolation and characterization of a new Methanofollis liminatans strain, $\mathrm{BM} 1$, is reported.

\section{METHODS}

Reference strains. Methanogenium tationis strain (DSM $2702^{\mathrm{T}}$ ) was obtained from the Deutsche Sammlung von Mikroorganismen und Zellkulturen (DSMZ, Braunschweig, Germany). Methanogenium liminatans strain GKZPZ (= DSM $4140^{\mathrm{T}}$ ) was isolated and (after deposition in the DSMZ) subcultured in this laboratory. The newly isolated strain BM1 has been deposited at the DSMZ as DSM 10196. The following strains were obtained from the Oregon Collection of Methanogens (Beaverton, OR, USA): Methanoculleus olentangyi RC/ER ${ }^{\mathrm{T}}$ (OCM 52 ${ }^{\mathrm{T}}$ ), Methanoculleus bourgensis MS2 ${ }^{\mathrm{T}}$ (OCM 15 $5^{\mathrm{T}}$ ), Methanocorpusculum bavaricum SZSXXZ ${ }^{\mathrm{T}}$ (OCM 127 $)$, Methanocorpusculum sinense China $Z^{\mathrm{T}}$ (OCM 128 ${ }^{\mathrm{T}}$ ) and Methanocorpusculum labreanum $\mathrm{Z}^{\mathrm{T}}\left(\mathrm{OCM}^{\mathrm{T}}\right)$.

Media, media preparation and cultivation. A synthetic basal medium (WHP medium) containing tungstate, with acetate and L-cysteine (the latter as a component of the reductant) as the sole organic carbon sources, was used for enrichment cultures, isolation procedures and cultivation of Methanogenium liminatans strains. WHP medium was based on the recipe described by Zellner \& Jargon (1997) except that yeast extract, peptone and additional sodium sulfate were omitted. WHP medium contained $1 \mu \mathrm{M}$ sodium tungstate and was used for the cultivation of strains DSM $2702^{\mathrm{T}}, \mathrm{GKZPZ}^{\mathrm{T}}$ and BM1. Substrates (e.g. sodium formate, sodium acetate, 2propanol, 2-butanol, cyclopentanol) were added from anaerobic, sterile stock solutions $(20 \%, \mathrm{w} / \mathrm{v}$ or $\mathrm{v} / \mathrm{v})$ as indicated to give concentrations of $0.5 \%(\mathrm{w} / \mathrm{v}$ or $\mathrm{v} / \mathrm{v})$ in the serum bottles. Cells were grown under $\mathrm{H}_{2} / \mathrm{CO}_{2}(4: 1, \mathrm{v} / \mathrm{v}$, $300 \mathrm{kPa}$ ) in $120 \mathrm{ml}$ serum bottles on a rotary shaker (150 r.p.m.). When other substrates were used instead of hydrogen, $\mathrm{N}_{2} / \mathrm{CO}_{2}(4: 1, \mathrm{v} / \mathrm{v}, 300 \mathrm{kPa})$ served as the gas atmosphere. For the preparation of large masses of cells, cells were grown in $\mathrm{H}_{2} / \mathrm{CO}_{2}(4: 1, v / v)$ at a flow rate of $50 \mathrm{l} \mathrm{h}^{-1}$ in a 121 fermenter (Biostat $\mathrm{S}$; Braun).

Methanogenium tationis was grown as described previously (Zabel et al., 1984). Methanoculleus olentangyi and Methanoculleus bourgensis were grown as described by Corder et al. (1983) and Ollivier et al. (1986), respectively. Methanocorpusculum labreanum was grown as described by Zhao et al. (1989). Methanocorpusculum sinense and Methanocorpusculum bavaricum were grown as described by Zellner et al. (1989a).

Source and habitat of strain BM1. Strain BM1 (= DSM 10196) was isolated from a butyrate-degrading, fluidized bed reactor inoculated with a culture originally derived from the upflow anaerobic sludge blanket (UASB) reactor from the wastewater treatment plant at a sugar refinery in Brühl, Germany (Zellner et al., 1991). The predominant methanogen in this bioreactor was an autofluorescent irregular coccus, similar in appearance to the new isolate (strain BM1) described here, and several other methanogens were identified immunologically (Zellner et al., 1991, 1997).

Enrichment and isolation of strain BM1. WHP medium with $\mathrm{H}_{2} / \mathrm{CO}_{2}(4: 1, \mathrm{v} / \mathrm{v}, 300 \mathrm{kPa})$ as substrate was inoculated with $1 \%(\mathrm{v} / \mathrm{v})$ bioreactor liquid and incubated at $37^{\circ} \mathrm{C}$. The gas phase was regularly replaced and autofluorescent, irregularly coccoid cells increased in number simultaneously with the formation of methane. This enriched culture was serially diluted into WHP medium and the highest dilution showing growth of the fluorescent, irregularly coccoid cells was again serially diluted. Aliquots $(0.1 \mathrm{ml})$ of the dilutions were then streaked on agar plates with WHP medium plus $2.5 \%(\mathrm{~W} / \mathrm{v})$ Oxoid agar (Unipath). All manipulations were performed in an anaerobic chamber (M. Braun) under a nitrogen atmosphere. The plates were transferred into a stainless steel anaerobic jar, pressurized to $300 \mathrm{kPa}$ with $\mathrm{H}_{2} / \mathrm{CO}_{2}(4: 1$, $\mathrm{v} / \mathrm{v}$ ) and incubated at $37^{\circ} \mathrm{C}$. After $20 \mathrm{~d}$ incubation, the gas pressure had dropped to $150 \mathrm{kPa}$, indicating gas consumption. The anaerobic jar was transferred into the anaerobic chamber. Cells were picked with a syringe needle from a well-isolated colony, injected into a $120 \mathrm{ml}$ serum bottle containing $20 \mathrm{ml}$ WHP medium under $\mathrm{H}_{2} / \mathrm{CO}_{2}(4: 1, \mathrm{v} / \mathrm{v}$, $300 \mathrm{kPa}$ ) and incubated at $37^{\circ} \mathrm{C}$. This procedure resulted in the isolation of strain BM1.

Microscopy. Phase-contrast and epifluorescence microscopy were carried out by using a Zeiss Axiophot microscope as described previously (Zellner et al., 1991). Motility was checked microscopically.

Analyses. Volatile fatty acids, alcohols, hydrogen and methane were analysed by GC (Zellner \& Winter, 1987). The Colour Gram 2 staining set from bioMérieux was used for Gram staining according to the manufacturer's instructions. 
Growth was measured as described previously (Zellner $e t$ al., 1989a).

Extraction of polar lipids and presumptive lipoquinones. Freeze-dried cells $(100 \mathrm{mg})$ were subjected to the two-stage extraction method described by Tindall (1990a, b). Respiratory lipoquinones were recovered in the first stage and polar lipids were recovered in the second stage. The presence or absence of respiratory lipoquinones was confirmed by TLC of the first stage extract on silica gel thin layers (Art. nr. 805023 , Macherey-Nagel) cut to $10 \times 10 \mathrm{~cm}$ squares, with hexane:tert-butylmethylether $(9: 1, \mathrm{v} / \mathrm{v})$ as the developing solvent.

Polar lipids were separated by two-dimensional TLC on silica gel thin layers (Macherey-Nagel, Art. nr. 818 135, which is a $10 \times 10 \mathrm{~cm}$ format). The plates were developed in chloroform:methanol: water $(65: 25: 4$, by vol. $)$ in the first direction, followed by chloroform:methanol:acetic acid: water $(80: 12: 15: 5$, by vol.) in the second direction. Total lipids were visualized with $5 \%$ dodecamolybdatophosphoric acid and specific functional groups were detected with periodate-Schiff $(\alpha$-glycols), ninhydrin (free amino groups), $\alpha$-naphthol (sugars), Dragendorf (quaternary nitrogen) and anisaldehyde- $\mathrm{H}_{2} \mathrm{SO}_{4}$ (sugars and terpenoids).

Extraction of ether lipids and TLC analysis. Ether lipids were extracted from $100 \mathrm{mg}$ freeze-dried cells by an acid hydrolysis method that did not hydrolyse diether lipids containing a hydroxyl group in the side chain. Diether lipids were subjected to double development in hexane:diethyl ether $(4: 1)$ to resolve phytanyl and sesterpanyl diether lipids (i.e. $\mathrm{C}_{20}: \mathrm{C}_{20}, \mathrm{C}_{20}: \mathrm{C}_{25}, \mathrm{C}_{25}: \mathrm{C}_{25}$ ). Tetraethers and diethers were separated in the solvent hexane:diethyl ether:acetic acid $(25: 25: 1$, by vol.).

Determination of $\mathbf{G}+\mathbf{C}$ content of DNA. DNA from strain $\mathrm{BM} 1$ was isolated and purified and the $\mathrm{mol} \% \mathrm{G}+\mathrm{C}$ content of the DNA was determined by HPLC according to Zellner et al. (1989a).

Sequence analysis of 16S rDNA and phylogenetic analysis. For Methanogenium tationis DSM $2702^{\mathrm{T}}$ and Methanogenium liminatans strains GKZPZ ${ }^{\mathrm{T}}$ and $\mathrm{BM} 1$, genomic DNA was extracted, the 16S rDNA was amplified by PCR and the sequences of the purified PCR products were analysed as described previously (Rainey et al., 1996). The sequencing reaction products were electrophoresed with a model 373A automated DNA sequencer (Applied Biosystems). The almost complete 16S rRNA genes of Methanogenium liminatans $\mathrm{GKZPZ}^{\mathrm{T}}$ (1396 nucleotides) and Methanogenium liminatans BM1 were determined. Approximately 1380 nucleotides of the Methanogenium liminatans GKZPZ ${ }^{\mathrm{T}} 16 \mathrm{~S}$ rRNA were also sequenced directly by the reverse transcriptase method (Rouvière et al., 1992). This sequence was $99.7 \%$ identical to the sequence obtained for the $16 \mathrm{~S}$ rRNA gene. The 16S rRNA gene sequence was used for the phylogenetic analysis. In addition, the 16S rRNA of Methanogenium tationis DSM $2702^{\mathrm{T}}$, Methanoculleus olentangyi $\mathrm{RC} / \mathrm{ER}^{\mathrm{T}}$, Methanoculleus bourgensis $\mathrm{MS}^{\mathrm{T}}$, Methanocorpusculum bavaricum SZSXXZ ${ }^{\mathrm{T}}$, Methanocorpusculum sinense China $\mathrm{Z}^{\mathrm{T}}$ and Methanocorpusculum labreanum $\mathrm{Z}^{\mathrm{T}}$ were sequenced directly by the reverse transcriptase method. About 1380 nucleotides were determined for each of these sequences.

The global phylogenetic positions of the strains were analysed by using the ARB database (Strunk \& Ludwig, 1997). 16S rRNA and rDNA sequences were compared with the existing 16S rDNA database of members of the order
Methanomicrobiales (Rouvière et al., 1992; Maidak et al., 1997). A greater degree of resolution among closely related taxa was obtained by using the ae2 editor (Maidak et al., 1997). A phylogenetic dendrogram was reconstructed using the treeing algorithm of De Soete (1983), based on similarity values which had been transformed into phylogenetic distance values that compensate for multiple substitutions at any given site in the sequence (Jukes \& Cantor, 1969). The programs NEIGHBOR-JOINING and MAXIMUM-LIKELIHOOD contained in the PHYLIP package (Felsenstein, 1993) were used in the construction of phylogenetic dendrograms (Saitou \& Nei, 1987). Bootstrap values were determined by using the programs NJFIND and NJBOOT of the PHYLIP package (Felsenstein, 1993).

Nucleotide sequence accession numbers. The sequences of 16S rDNA of Methanogenium liminatans strain DSM $4140^{\mathrm{T}}$ and strain BM1 were deposited in the EMBL database under the accession numbers Y16428 and Y16429, respectively. The 16S rRNA sequences of Methanogenium tationis DSM $2702^{\mathrm{T}}$, Methanoculleus bourgensis $\mathrm{MS} 2^{\mathrm{T}}\left(=\mathrm{OCM} 15^{\mathrm{T}}\right.$, DSM $3045^{\mathrm{T}}$ ) and Methanoculleus olentangyi $\mathrm{RC} / \mathrm{ER}^{\mathrm{T}}$ (= OCM $52^{\mathrm{T}}$, DSM $\left.2772^{\mathrm{T}}\right), \quad$ Methanocorpusculum bavaricum SZSXXZ ${ }^{\mathrm{T}}, \quad\left(=\mathrm{OCM} 127^{\mathrm{T}}, \quad\right.$ DSM $\left.4179^{\mathrm{T}}\right)$, Methanocorpusculum sinense China $\mathrm{Z}^{\mathrm{T}}$ (= OCM $128^{\mathrm{T}}$, DSM $4274^{\mathrm{T}}$ ) and Methanocorpusculum labreanum $\mathrm{Z}^{\mathrm{T}}\left(=\mathrm{OCM} \mathrm{1}^{\mathrm{T}}\right.$, DSM $4855^{\mathrm{T}}$ ) were deposited in GenBank under the accession numbers AF095266-AF095272, respectively. Other sequences utilized were obtained from EMBL (Methanoculleus palmeoli, Y16382) or the Ribosomal Database Project (Maidak et al., 1997).

\section{RESULTS AND DISCUSSION}

\section{Morphology of strains, S-layer architecture and composition}

Cells of the newly isolated strain BM1 were highly irregular cocci. Some cells also had a ring-shaped appearance under phase-contrast microscopy. The cells were $1 \cdot 25-2.0 \mu \mathrm{m}$ in diameter, stained Gramnegative and were non-motile. The addition of $1 \%$ $(\mathrm{w} / \mathrm{v})$ SDS led to lysis of cells of Methanogenium liminatans $\mathrm{GKZPZ}^{\mathrm{T}}$ and strain $\mathrm{BM} 1$, indicating a cell envelope with a proteinaceous cell wall. With the exception of Methanogenium liminatans strains, which appear as ring-shaped cells under phase-contrast microscopy (Zellner et al., 1990), the species described to date of the genera Methanogenium and Methanoculleus are irregular cocci and are indistinguishable from each other (Boone et al., 1993). However, some differences in cell envelope composition have been observed (Table 1). All irregularly coccoid methanogens within the order Methanomicrobiales possess hexagonal Slayer lattices consisting of glycoprotein subunits with $M_{\mathrm{r}}$ ranging from 90000 to 155000 . However, only methanogens belonging to the family Methanocorpusculaceae have an S-layer glycoprotein with $M_{\mathrm{r}}$ ranging from 90000 to 94000 . The $M_{\mathrm{r}}$ of S-layer glycoprotein subunits of genera of the family Methanomicrobiaceae range from 101000 to 155000 .

During the course of compiling this paper, the incorrect orthography of Methanoculleus thermophilicus was noticed which, according to Rule 61 of the 
Table 1. S-layers of irregularly coccoid methanogens of the families Methanomicrobiaceae, Methanoplanaceae and Methanocorpusculaceae

\begin{tabular}{|c|c|c|c|c|}
\hline Strain & DSM no. & $\begin{array}{l}\text { Lattice } \\
\text { constant } \\
\text { c/c }(\mathbf{n m})^{*}\end{array}$ & $\begin{array}{c}\text { Glycoprotein } \\
\text { subunit } \\
M_{\mathrm{r}}\left(\times 10^{-3}\right)\end{array}$ & Reference \\
\hline \multicolumn{5}{|l|}{ Genus Methanofollis } \\
\hline M. tationis Chile $9^{\mathrm{T}}$ & $2702^{\mathrm{T}}$ & ND & 120 & Zabel et al. (1984); Zellner et al. (1998) \\
\hline M. liminatans $\mathrm{GKZPZ}$ & $4140^{\mathrm{T}}$ & $15 \cdot 4$ & 118 & Zellner et al. $(1990,1998)$ \\
\hline \multicolumn{5}{|l|}{ Genus Methanoculleus } \\
\hline M. marisnigri $\mathrm{JR} 1^{\mathrm{T}}$ & $1498^{\mathrm{T}}$ & ND & 138 & Zellner et al. (1990) \\
\hline M. olentangyi $\mathrm{RC} / \mathrm{ER}^{\mathrm{T}}$ & $2772^{\mathrm{T}}$ & $15 \cdot 4$ & 132 & Zellner et al. (1990) \\
\hline M. bourgensis $\mathrm{MS}^{\mathrm{T}}$ & $3045^{\mathrm{T}}$ & $15 \cdot 4$ & 101 & Zellner et al. (1990) \\
\hline M. thermophilus $\mathrm{CR}-\mathrm{1}^{\mathrm{T}}$ & $2373^{\mathrm{T}}$ & ND & 130 & Zabel et al. (1985) \\
\hline M. thermophilus UCLA & 2624 & ND & 130 & Zabel et al. (1985) \\
\hline M. thermophilus Ratisbona & 2640 & ND & 130 & Zabel et al. (1985) \\
\hline M. palmolei INSLUZ & $4273^{\mathrm{T}}$ & $15 \cdot 2$ & 120 & Zellner et al. (1998) \\
\hline \multicolumn{5}{|l|}{ Genus Methanogenium } \\
\hline M. cariaci $\mathrm{JR} 1^{\mathrm{T}}$ & $1497^{\mathrm{T}}$ & $14 \cdot 0$ & 117 & Zellner et al. (1990) \\
\hline M. frittonii $\mathrm{FR}-4^{\mathrm{T}}$ & $2832^{\mathrm{T}}$ & $15 \cdot 4$ & 106 & Zellner et al. (1990) \\
\hline \multicolumn{5}{|l|}{ Genus Methanolacinia } \\
\hline M. paynteri $\mathrm{G} 2000^{\mathrm{T}}$ & $2545^{\mathrm{T}}$ & $15 \cdot 3$ & $155 \dagger$ & Zellner et al. (1989c) \\
\hline \multicolumn{5}{|l|}{ Genus Methanoplanus } \\
\hline M. limicola $\mathrm{M}^{\mathrm{T}}$ & $2279^{\mathrm{T}}$ & $14 \cdot 0$ & 143 & Zellner et al. (1989a) \\
\hline M. endosymbiosus $\mathrm{MCl}^{\mathrm{T}}$ & $3599^{\mathrm{T}}$ & ND & 110 & Zellner et al. (1989a) \\
\hline \multicolumn{5}{|l|}{ Genus Methanocorpusculum } \\
\hline$M$. parvum $\mathrm{XII}^{\mathrm{T}}$ & $3823^{\mathrm{T}}$ & $14 \cdot 3$ & 90 & Zellner et al. (1989a) \\
\hline M. bavaricum $\mathrm{SZSXXZ}{ }^{\mathrm{T}}$ & $4179^{\mathrm{T}}$ & $16 \cdot 0$ & 94 & Zellner et al. (1989a) \\
\hline$M$. sinense $\mathrm{CHINAZ}$ & $4274^{\mathrm{T}}$ & $15 \cdot 8$ & 92 & Zellner et al. (1989a) \\
\hline M. aggregans $\mathrm{MSt}^{\mathrm{T}}$ & $3027^{\mathrm{T}}$ & $15 \cdot 4$ & 92 & P. Messner \& G. Zellner, unpublished \\
\hline
\end{tabular}

ND, Not determined.

* Centre-to-centre spacing of hexagonally arranged protein subunits of S-layer.

$\dagger$ A second, weaker band with an $M_{\mathrm{r}}$ of 135000 that reacted with PAS stain presumably represented a degradation product or a less glycosylated precursor.

Bacteriological Code (Lapage et al., 1992), may be corrected to Methanoculleus thermophilus (corrig.).

\section{Culture conditions and substrates for growth and methanogenesis}

The optimal growth temperature of strain BM1 was about $37-40^{\circ} \mathrm{C}$. No growth was obtained below $20^{\circ} \mathrm{C}$ or above $45^{\circ} \mathrm{C}$. The optimal pH was about 7 . Growth and methane production were observed on $\mathrm{H}_{2} / \mathrm{CO}_{2}$, formate, 2-propanol $/ \mathrm{CO}_{2}$ and 2-butanol $/ \mathrm{CO}_{2}$. Growth and methane production by strain BM1 on potential substrates was as follows (maximal $\mathrm{OD}_{578}$ obtained/total methane produced per $20 \mathrm{ml}$ culture in a $120 \mathrm{ml}$ serum bottle): $\mathrm{H}_{2} / \mathrm{CO}_{2}(0 \cdot 86 / 3285 \mu \mathrm{mol})$, formate $\quad(0 \cdot 14 / 172 \mu \mathrm{mol}), \quad 2$-propanol $/ \mathrm{CO}_{2}$ $(0 \cdot 06 / 52 \mu \mathrm{mol}), 2$-butanol $/ \mathrm{CO}_{2}(0.04 / 44 \mu \mathrm{mol})$ and cyclopentanol $/ \mathrm{CO}_{2}(0 \cdot 001 / 21 \mu \mathrm{mol})$. Thus, except for cyclopentanol $/ \mathrm{CO}_{2}$, which supported only methanogenesis, all these substrates supported both growth and methanogenesis. The secondary and cyclic alcohols were oxidized to the respective ketones. Strain BM1 did not grow or produce methane in media with acetate, methanol, methylamines, ethanol or 1-propanol as substrate. In contrast, Methanogenium tationis DSM $2702^{\mathrm{T}}$ did not grow or produce methane on 2-propanol $/ \mathrm{CO}_{2}$ or 2-butanol/ $\mathrm{CO}_{2}$ (Zellner \& Winter, 1987) or cyclopentanol/ $\mathrm{CO}_{2}$. Acetate was required for growth of strain BM1 on formate. Thus, while strain BM1 resembled Methanogenium liminatans more closely in terms of substrate utilization, it could not be distinguished from other species of the genera Methanoculleus and Methanogenium on this basis (Table 2).

\section{Cell physiology}

The original descriptions of Methanogenium tationis and Methanogenium liminatans were supplemented by material on the utilization of secondary and cyclic 
Table 2. Phenotypic features of irregularly coccoid strains of the families Methanomicrobiaceae and Methanoplanaceae

\begin{tabular}{|c|c|c|c|c|c|c|c|c|c|c|c|}
\hline \multirow[t]{2}{*}{ Strain } & \multirow[t]{2}{*}{ DSM no. } & \multirow[t]{2}{*}{ Cell size $(\mu \mathrm{m})$} & \multirow[t]{2}{*}{ Flagella } & \multicolumn{4}{|c|}{ Substrates* } & \multirow[t]{2}{*}{ Min. $t_{D}(h)$} & \multirow[t]{2}{*}{ Growth temp. $\left({ }^{\circ} \mathrm{C}\right) \dagger$} & \multirow{2}{*}{$\begin{array}{c}\mathrm{G}+\mathbf{C} \text { content } \\
(\mathrm{mol} \%)_{+}^{+}\end{array}$} & \multirow[t]{2}{*}{ Reference } \\
\hline & & & & $\mathbf{H}$ & $\mathbf{F}$ & $\mathbf{2 P}$ & 2B & & & & \\
\hline \multicolumn{12}{|l|}{ Genus Methanofollis } \\
\hline M. tationis Chile $9^{\mathrm{T}}$ & $2702^{\mathrm{T}}$ & $1 \cdot 5-3+0$ & + & + & + & - & - & 12 & $37-40 / 25-45$ & 54 & Zabel et al. (1984) \\
\hline M. liminatans GKZPZ ${ }^{T}$ & $4140^{\mathrm{T}}$ & $1 \cdot 25-2 \cdot 0$ & + & + & + & + & + & 7.5 & $40 / 25-45$ & $59 \cdot 3$ & Zellner et al. (1990) \\
\hline M. liminatans BM1 & 10196 & $1.25-2.0$ & ND & + & + & + & + & ND & $40 / 20-45$ & $60 \cdot 0^{b}$ & This paper \\
\hline \multicolumn{12}{|l|}{ Genus Methanoculleus } \\
\hline M. marisnigri $\mathrm{JR} 1^{\mathrm{T}}$ & $1498^{\mathrm{T}}$ & $1 \cdot 3 / 1-2$ & + & + & + & + & + & 10 & $20-25 / 10-45$ & $61-62^{a}$ & Romesser et al. (1979) \\
\hline$M$. olentangyi $\mathrm{RC} / \mathrm{ER}^{\mathrm{T}}$ & $2772^{\mathrm{T}}$ & $1 \cdot 0-1 \cdot 5$ & - & + & + & $(+)$ & $(+)$ & $10 \cdot 9$ & $37 / 30-45$ & $54 \cdot 4^{a}$ & Corder et al. (1983) \\
\hline$M$. bourgensis $§ \mathrm{MS} 2^{\mathrm{T}}$ & $3045^{\mathrm{T}}$ & $1 \cdot 0-2 \cdot 0$ & + & + & + & + & + & $18 \cdot 0$ & $37 / 25-55$ & $59^{a}, 56-57$ & Ollivier et al. (1986) \\
\hline$M$. thermophilus $\mathrm{CR}-1^{\mathrm{T}}$ & $2373^{\mathrm{T}}$ & $0 \cdot 8-1 \cdot 3$ & + & + & + & ND & ND & $2 \cdot 5$ & $55 / 37-65$ & $59 \cdot 5^{a}, 57-59$ & Rivard \& Smith (1982) \\
\hline$M$. thermophilus UCLA & 2624 & $0.7-1 \cdot 8$ & + & + & + & - & - & $1 \cdot 8$ & $55-60 /<70$ & $56,59 \cdot 7$ & Ferguson \& Mah (1983) \\
\hline M. thermophilus Ratisbona & 2640 & $0 \cdot 9-1 \cdot 5$ & + & + & + & - & - & 3.4 & $58 / 30-60$ & 57 & Zabel et al. (1985) \\
\hline M. thermophilus TCI & 3915 & $0.6-1.5$ & NR & + & + & + & + & NR & $55 / 30-60$ & $54 \cdot 7$ & Widdel et al. (1988) \\
\hline M. oldenburgensis & $6216^{\mathrm{T}}$ & $1 \cdot 0$ & - & + & + & - & - & 3.8 & $45 / 20-50$ & $48 \cdot 6$ & Blotevogel et al. (1991) \\
\hline M. palmolei INSLUZ ${ }^{\mathrm{T}}$ & $4273^{\mathrm{T}}$ & $1 \cdot 25-2 \cdot 0$ & + & + & + & + & + & $13 \cdot 5$ & $40 / 21-51$ & $59 \cdot 0$ & Zellner et al. (1998) \\
\hline \multicolumn{12}{|l|}{ Genus Methanogenium } \\
\hline M. cariaci $\mathrm{JR}^{\mathrm{T}}$ & $1497^{\mathrm{T}}$ & $<2 \cdot 6,1-3$ & - & + & + & + & + & $11 \cdot 0$ & $37-45 / 15-50$ & $51 \cdot 6^{a}$ & Romesser et al. (1979) \\
\hline M. organophilum $\mathrm{CV}^{\mathrm{T}}$ & $3596^{\mathrm{T}}$ & $0.5-1.5$ & - & + & + & + & - & $\mathrm{ND}$ & $30-35 / 15-39$ & $46 \cdot 7$ & Widdel et al. (1988) \\
\hline M. frittonii $\mathrm{FR}-4^{\mathrm{T}}$ & $2832^{\mathrm{T}}$ & $1-2 \cdot 5$ & - & + & - & - & - & $1-2$ & $57 / 26-62$ & $49 \cdot 2$ & Harris et al. (1984) \\
\hline$M$. frigidum Ace-2 & [SMCC459W] & $1 \cdot 2-2 \cdot 5$ & - & + & + & ND & ND & $69 \cdot 6$ & $15 / 0-17$ & $\mathrm{ND}$ & Franzmann et al. (1997) \\
\hline \multicolumn{12}{|l|}{ Genus Methanolacinia } \\
\hline M. paynteri G-2000 $0^{\mathrm{T}}$ & $2545^{\mathrm{T}}$ & $0.6 \times 1.5-2.5$ & + & + & - & + & + & $\mathrm{ND}$ & $40 / 20-45$ & $45^{a}, 38$ & Zellner et al. (1989c) \\
\hline \multicolumn{12}{|l|}{ Genus Methanoplanus } \\
\hline M. limicola $\mathrm{M}^{\mathrm{T}}$ & $2279^{\mathrm{T}}$ & $1-3 \times 0 \cdot 1-0.25$ & + & + & + & - & - & ND & $40 / 17-41$ & $47 \cdot 5$ & Wildgruber et al. (1982) \\
\hline M. endosymbiosus $\mathrm{MC1}^{\mathrm{T}}$ & $3599^{\mathrm{T}}$ & $1 \cdot 6-3 \cdot 4$ & + & + & + & ND & ND & 7 & $32 / 16-36$ & $38 \cdot 7$ & van Bruggen et al. (1986) \\
\hline
\end{tabular}

NR, Not reported; ND, not determined.

${ }^{*} \mathrm{H}, \mathrm{H}_{2} / \mathrm{CO}_{2} ; \mathrm{F}$, formate; 2P, 2-propanol $/ \mathrm{CO}_{2} ; 2 \mathrm{~B}, 2$-butanol $/ \mathrm{CO}_{2}$. None of the strains utilized acetate, methanol or methylamines. Methanogenium organophilum utilized ethanol, 1-propanol and 1-butanol in addition. Data on alcohol utilization partly taken from Zellner \& Winter (1987). In addition, both Methanofollis liminatans strains, GKZPZ and BM1, Methanoculleus palmolei and Methanolacinia paynteri utilized cyclopentanol $/ \mathrm{CO}_{2}$ with concomitant production of cyclopentanone and $\mathrm{CH}_{4}$, while Methanofollis tationis could not utilize cyclopentanol/ $\mathrm{CO}_{2} \cdot(+)$, Weakly positive.

$\dagger$ Growth temperature is given as optimum temperature/temperature range.

$\ddagger \mathrm{G}+\mathrm{C}$ content of DNA was determined by $T_{\mathrm{m}}$ unless otherwise indicated, in which case it was determined by buoyant density $(a)$ or $\operatorname{HPLC}(b)$.

$\S$ Methanoculleus olentangyi and Methanoculleus bourgensis are apparently subjective synonyms (Xun et al., 1989; Boone et al., 1993).

acids from Zellner \& Winter (1987) and Bleicher et al. (1989). Methanogenium liminatans contains a secondary alcohol dehydrogenase activity that is devoid of zinc and is dependent on factor $\mathrm{F}_{420}$ (Bleicher \& Winter, 1991).

The pterin of Methanogenium tationis has a structural modification not found in other methanogens and is called tatiopterin. Tatiopterin lacks a 7-methyl substituent but has both a glutamyl and an aspartyl residue conjugated to the phosphoglutaryl moiety (Raemakers-Franken et al., 1989) and can be distinguished from methanopterin and sarcinapterin (Keltjens et al., 1983; DiMarco et al., 1990).

\section{Presumptive respiratory lipoquinones of Methanogenium tationis and Methanogenium liminatans}

Examination of Methanogenium tationis DSM $2702^{\mathrm{T}}$ and Methanogenium liminatans $\mathrm{GKZPZ}^{\mathrm{T}}$ for the presence of respiratory lipoquinones indicated that none were present, a finding consistent with results obtained for all other members of the methanogenic Archaea examined to date (B. J. Tindall, unpublished data).

\section{Lipids of Methanogenium tationis and Methanogenium liminatans}

Both diether- and tetraether-linked glycerol lipids were present in Methanogenium tationis DSM $2702^{\mathrm{T}}$ and Methanogenium liminatans GKZPZ ${ }^{\mathrm{T}}$ (data not shown). The diether lipids were diphytanyl glycerol diethers, while the tetraether lipids showed no evidence of cyclization and only acyclic $\mathrm{C}_{40}: \mathrm{C}_{40}$ dibiphytanyl tetraethers were present. These results are consistent with the results from other members of the family Methanomicrobiaceae examined to date (Grant et al., 1985; Zellner et al., 1989c; Blotevogel et al., 1991; B. J. Tindall \& G. Zellner, unpublished data).

The major polar lipids present in Methanogenium tationis DSM $2702^{\mathrm{T}}$ and Methanogenium liminatans GKZPZ $^{\mathrm{T}}$ were glycolipids, phospholipids and phosphoglycolipids (Fig. 1). The major phospholipids present were ether derivatives of phosphatidyl glycerol, phosphopentanetetrol amine and phosphopentanetetrol trimethylamine. The major glycolipid present was a diglycosyl ether lipid, the nature of the sugars and their mode of linkage not being determined. A single major phosphoglycolipid was also detected. The 
(a)

1

2

3

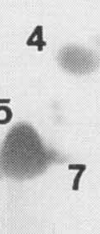

2.

(b)

Fig. 1. Thin-layer chromatograms of the polar lipids of (a) Methanogenium tationis DSM $2702^{\top}$ and (b) Methanogenium liminatans $\mathrm{GKZPZ}^{\top}$. Spots are identified as: 1, phosphatidyl glycerol; 2, phosphatidyl pentanetetrol amine; 3, diglycosyl diether; 4, phosphatidyl pentanetetrol trimethylamine; 5, phosphoglycolipid; 6, phosphoglycolipid; 7, amino-phosphoglycolipid; 8, amino-phospholipid.

presence of aminopentanetetrol-containing phospholipids is characteristic of members of the family Methanomicrobiaceae. Moreover, a detailed analysis of the total polar lipid composition of the various taxa within this group indicates that there are clear differences between the various taxa currently described (Grant et al., 1985; Zellner et al., 1989a, c; Blotevogel et al., 1991; B. J. Tindall \& G. Zellner, unpublished data). Thus, the chemical composition of the cell may be a useful way of differentiating genera in this phyletic group.

Although it is not known whether members of the Methanocorpusculaceae also contain these unusual aminopentanetetrol-containing phospholipids, the polar lipid composition of members of this family is

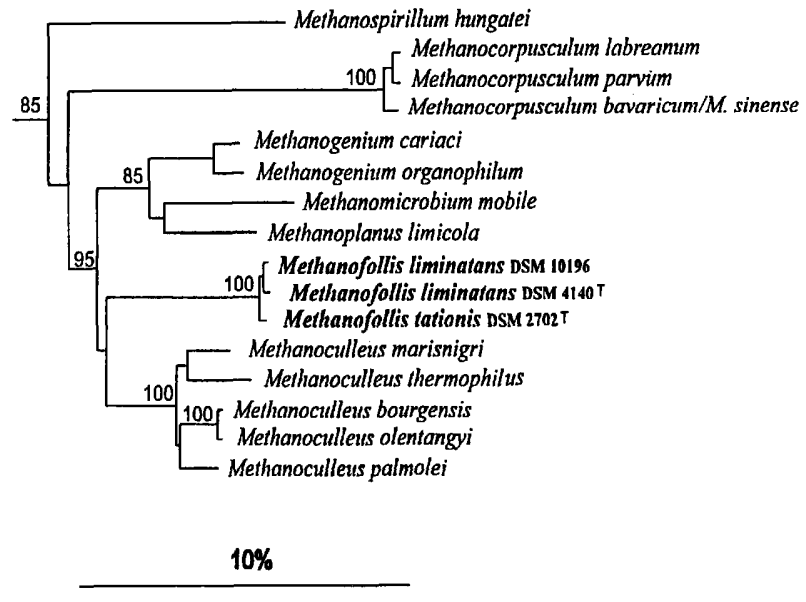

Fig. 2. Dendrogram showing the phylogenetic positions of Methanofollis tationis DSM $2702^{\top}$, Methanofollis liminatans GKZPZ $^{\top}$ (=DSM 4140') and Methanofollis liminatans BM1 (=DSM 10196) within the family Methanomicrobiaceae. Numbers at branch points represent percentage bootstrap support. Bar, $10 \%$ sequence divergence.

sufficiently different to distinguish them from the members of the family Methanomicrobiaceae (Zellner et al., 1989a). The fact that members of the family Methanocorpusculaceae have a distinct polar lipid pattern would appear to contradict the 16S rDNA sequence data, since this family appears to branch within the family Methanomicrobiaceae. However, the branching order of some groupings within the members of the order Methanomicrobiales is uncertain. Such uncertainties in branching order, particularly where the pendant edges of the dendrogram are long in relation to the length of internal branches, has been already documented.

The presence of identical polar lipids in both Methanogenium tationis and Methanogenium liminatans suggests that these features are not characteristic of the individual species but indicative of a higher taxonomic group. Although certain aspects of their polar lipid pattern are similar to other members of the family Methanomicrobiaceae, there are differences in the details of the polar lipid patterns which may be regarded as genus-specific markers.

\section{Phylogenetic position}

Sequencing of the 16S rRNA and rDNA was performed to determine the phylogenetic relationship of Methanogenium tationis strain DSM $2702^{\mathrm{T}}$ and Methanogenium liminatans strains GKZPZ ${ }^{\mathrm{T}}$ and $\mathrm{BM} 1$ to other members of the family Methanomicrobiaceae. Analysis of these sequences indicated that the three strains form a phylogenetically coherent group almost equidistant from the genus Methanoculleus and other Methanogenium species (Fig. 2). The $\mathrm{G}+\mathrm{C}$ content of the DNA of strain BM1 was determined to be $60.0 \mathrm{~mol} \%$, i.e. nearly identical to that of Methano- 
genium liminatans GKZPZ (Zellner et al., 1990). Thus, the $\mathrm{G}+\mathrm{C}$ content of DNA of this group ranges from 54 to $60 \mathrm{~mol} \%$.

On the basis of the similarity in $\mathrm{G}+\mathrm{C}$ content of DNA, substrate utilization patterns and other phenotypic properties, strain BM1 is assigned to the same species as Methanogenium liminatans GKZPZ ${ }^{\mathrm{T}}$. On the basis of the 16S rDNA sequence and chemotaxonomic data, which indicate that Methanogenium tationis and Methanogenium liminatans represent a distinct phyletic group within the family Methanomicrobiaceae, it is proposed that they be placed in a new genus, for which the name Methanofollis gen. nov., is proposed. The strains are described as Methanofollis tationis DSM $2702^{\mathrm{T}}$ gen. nov., comb. nov., Methanofollis liminatans $\mathrm{GKZPZ}^{\mathrm{T}}$ comb. nov. and Methanofollis liminatans BM1.

The 16S rRNA sequences of Methanocorpusculum bavaricum and Methanocorpusculum sinense have a missing stretch of $40 \mathrm{bp}$. The remainders of their sequences are $100 \%$ and about $99.6 \%$ identical to Methanocorpusculum parvum and Methanocorpusculum labreanum, respectively, which are themselves $99.8 \%$ identical. Therefore, the four Methanocorpusculum species are highly related. About 1100 nucleotides were used for the alignment of Methanocorpusculum bavaricum and Methanocorpusculum sinense 16S rRNA sequences, while 1150 nucleotides were used for the Methanocorpusculum parvum and Methanocorpusculum labreanum sequences.

\section{Description of Methanofollis gen. nov.}

Methanofollis (Me.tha.no.fol'lis. M.L. n. methanum methane; M.L. n. follis a bag; Methanofollis a methane-producing bag).

Irregular cocci, $1 \cdot 5-3.0 \mu \mathrm{m}$ in diameter, with a proteinaceous, SDS-sensitive S-layer. Cells stain Gramnegative. Some strains are motile. Obligately anaerobic, no microaerophilic or aerobic growth. Mesophilic (range $\geqslant 15$ to $<45^{\circ} \mathrm{C}$ ). Substrates for growth and methane production are $\mathrm{H}_{2} / \mathrm{CO}_{2}$ or formate; some species may use 2-propanol $/ \mathrm{CO}_{2}$, 2-butanol/ $\mathrm{CO}_{2}$ and cyclopentanol $/ \mathrm{CO}_{2}$. Sulfate is not reduced. The ether lipids comprise diphytanyl diether and dibiphytanyl tetraethers. No evidence for significant quantities of other derivatives, including the presence of pentacyclic rings. The major polar lipids are phospholipids, glycolipids and phosphoglycolipids. Among these the predominant compounds are the ether derivatives of phosphatidyl glycerol, diglycosyl glycolipid, phosphopentanetetrol amine, phosphopentanetetrol trimethylamine and a phosphoglycolipid. Minor components include a glycolipid, a phospholipid, an amino-phospholipid, a phosphoglycolipid and an amino-phosphoglycolipid. This pattern differs in detail from other members of the family Methanomicrobiaceae. The $\mathrm{G}+\mathrm{C}$ content of DNA of known strains ranges from 54 to $60 \mathrm{~mol} \%\left(T_{\mathrm{m}}\right.$ and
HPLC). Habitats are anaerobic high-rate wastewater bioreactors or solfataric fields. The type species of the genus is Methanofollis tationis comb. nov.

\section{Description of Methanofollis tationis comb. nov.}

Irregularly coccoid cells, $1.5-3 \mu \mathrm{m}$ in diameter, with a proteinaceous, SDS-sensitive S-layer. Cells stain Gram-negative. Cells are motile or non-motile. Obligately anaerobic, no microaerophilic or aerobic growth. Strains are mesophilic (range $\geqslant 15$ to $<45^{\circ} \mathrm{C}$ ). Substrates for growth and methane production are $\mathrm{H}_{2} / \mathrm{CO}_{2}$ and formate. Methanol, methylamines, ethanol, 2-propanol $/ \mathrm{CO}_{2}$, 2-butanol $/ \mathrm{CO}_{2}$ and cyclopentanol $/ \mathrm{CO}_{2}$ are not utilized. Cells contain tatiopterin, a modified pterin distinct from methanopterin and sarcinapterin. Lipid composition as that described for the genus. The $\mathrm{G}+\mathrm{C}$ content of DNA of the only strain known so far is $54 \mathrm{~mol} \%\left(T_{\mathrm{m}}\right)$. The type strain is DSM $2702^{\mathrm{T}}$ and was isolated from a solfataric field on Mount Tatio in the Atacama desert in northern Chile.

\section{Description of Methanofollis liminatans comb. nov.}

Irregularly coccoid or ring-shaped cells, $1 \cdot 25-2 \cdot 0 \mu \mathrm{m}$ in diameter, with a proteinaceous, SDS-sensitive S-layer. Cells stain Gram-negative. Some strains may be motile. Obligately anaerobic, no microaerophilic or aerobic growth. Cells are mesophilic (range $\geqslant 15^{\circ} \mathrm{C}$ to $<45^{\circ} \mathrm{C}$ ) with an optimum at $40^{\circ} \mathrm{C}$. Substrates for growth and methane production are $\mathrm{H}_{2} / \mathrm{CO}_{2}$, formate, 2-propanol $/ \mathrm{CO}_{2}$, 2-butanol $/ \mathrm{CO}_{2}$ and cyclopentanol/ $\mathrm{CO}_{2}$. Secondary and cyclic alcohols are oxidized to the respective ketones. Methanol, methylamines, ethanol and acetate are not utilized as catabolic substrates. Cells of GKZPZ ${ }^{\mathrm{T}}$ contain a secondary alcohol dehydrogenase dependent on $\mathrm{F}_{420}$ and devoid of $\mathrm{Zn}$. Lipid composition as that described for the genus. The $\mathrm{G}+\mathrm{C}$ content of DNA of the type strain is $60 \mathrm{~mol} \%$ $\left(T_{\mathrm{m}}\right)$. The type strain is GKZPZ ${ }^{\mathrm{T}}\left(=\mathrm{DSM} 4140^{\mathrm{T}}\right)$, isolated from an industrial wastewater bioreactor (Biohochreaktor, Hoechst, Kelsterbach, Frankfurt, Germany). Strain BM1 (= DSM 10196) is a reference strain, isolated from a methane-producing fluidized bed reactor operated with synthetic wastewater containing butyrate and present in a full-scale UASB reactor treating sugar refinery wastewater anaerobically in Brühl, Germany.

\section{ACKNOWLEDGEMENTS}

This investigation was supported in part by grants of the Deutsche Forschungsgemeinschaft. Part of the practical work of G.Z. was performed in the Institute of Microbiology, University of Hannover, Germany, and was compiled during a period as a Senior Research Associate of the Wageningen Agricultural University, financially supported by WIMEK (Wageningen Institute for Environment and Climate, Wageningen, The Netherlands). W. B.W. received support from the US Environmental Protection Agency, contract AERL-9003. C.R.W. received support from the 
National Science Foundation, grant DEB-9306171. The $\mathrm{G}+\mathrm{C}$ content of DNA of strain BM1 was determined by Mrs Inge Reupke. We wish to thank Mrs Ulrike Mendrock for her help with the molecular work.

\section{REFERENCES}

Bleicher, K. \& Winter, J. (1991). Purification and properties of $\mathrm{F}_{420^{-}}$and $\mathrm{NADP}^{+}$-dependent alcohol dehydrogenases of Methanogenium liminatans and Methanobacterium palustre, specific for secondary alcohols. Eur J Biochem 200, 43-51.

Bleicher, K., Zellner, G. \& Winter, J. (1989). Growth of methanogens on cyclopentanol $/ \mathrm{CO}_{2}$ and specificity of alcohol dehydrogenase. FEMS Microbiol Lett 59, 307-312.

Blotevogel, K.-H., Gahl-Janßen, R., Jannsen, S., Fischer, U., Pilz, F., Auling, G., Macario, A. J. L. \& Tindall, B. J. (1991). Isolation and characterization of a novel mesophilic, fresh-water methanogen from river sediment, Methanoculleus oldenburgensis sp. nov. Arch Microbiol 157, 54-59.

Boone, D. R., Whitman, W. B. \& Rouvière, P. (1993). Diversity and taxonomy of methanogens. In Methanogenesis: Ecology, Physiology, Biochemistry and Genetics, pp. 35-80. Edited by J. G. Ferry. New York: Chapman \& Hall.

van Bruggen, J. J. A., Zwart, K. B., Hermans, J. G. F., van Hove, E. M., Stumm, C. K. \& Vogels, G. D. (1986). Isolation and characterization of Methanoplanus endosymbiosus sp. nov., an endosymbiont of the marine sapropelic ciliate Metopus contortus Quennerstedt. Arch Microbiol 144, 367-374.

Corder, R. E., Hook, L. A., Larkin, J. M. \& Frea, J. I. (1983). Isolation and characterization of two new methane-producing cocci: Methanogenium olentangyi, sp. nov., and Methanococcus deltae, sp. nov. Arch Microbiol 134, 28-32.

De Soete, G. (1983). A least squares algorithm for fitting additive trees to proximity data. Psychometrika 48, 621-626.

DiMarco, A. A., Bobik, T. A. \& Wolfe, R. S. (1990). Unusual coenzymes of methanogenesis. Annu Rev Biochem 59, 355-394.

Felsenstein, J. (1993). PHYLIP (phylogeny interference package), version 3.5c. University of Washington, Seattle, WA, USA.

Ferguson, T. J. \& Mah, R. A. (1983). Isolation and characterization of an $\mathrm{H}_{2}$-oxidizing thermophilic methanogen. Appl Environ Microbiol 45, 265-274.

Franzmann, P. D., Liu, Y., Balkwill, D. L., Aldrich, H. C., Conway de Macario, E. \& Boone, D. R. (1997). Methanogenium frigidum sp. nov., a psychrophilic, $\mathrm{H}_{2}$-using methanogen from Ace Lake, Antarctica. Int J Syst Bacteriol 47, 1068-1072.

Grant, W. D., Pinch, G., Harris, J. E., De Rosa, M. \& Gambacorta, A. (1985). Polar lipids in methanogen taxonomy. J Gen Microbiol 131, 3277-3286.

Harris, J. E., Pinn, P. A. \& Davis, R. P. (1984). Isolation and characterization of a novel thermophilic, freshwater methanogen. Appl Environ Microbiol 48, 1123-1128.

Jukes, T. H. \& Cantor, C. R. (1969). Evolution of protein molecules. In Mammalian Protein Metabolism, pp. 21-132. Edited by H. N. Munro. New York: Academic Press.

Keltjens, J. T., Huberts, M. J., Laarhoven, W. H. \& Vogels, G. D. (1983). Structural elements of methanopterin, a novel pterin present in Methanobacterium thermoautotrophicum. Eur $J$ Biochem 130, 537-544.

Koga, Y., Nishihara, M., Morii, H. \& Akagawa-Matsushita, M. (1993). Ether polar lipids of methanogenic bacteria: structures, comparative aspects, and biosyntheses. Microbiol Rev 57, 164-182.
Lapage, S. P., Sneath, P. H. A., Lessel, E. F., Skerman, V. B. D. Seeliger, H. P. R. \& Clark, W. A. (editors) (1992). International Code of Nomenclature of Bacteria, (1990 Revision). Bacteriological Code. Washington, DC: American Society for Microbiology.

Maestrojuán, G. M., Boone, D. R., Xun, L., Mah, R. A. \& Zhang, L. (1990). Transfer of Methanogenium bourgense, Methanogenium marisnigri, Methanogenium olentangyi, and Methanogenium thermophilicum to the genus Methanoculleus gen. nov., emendation of Methanoculleus marisnigri and Methanogenium, and description of new strains of Methanoculleus bourgense and Methanoculleus marisnigri. Int J Syst Bacteriol 40, 117-122.

Maidak, B. L., Olsen, G. J., Larsen, N., Overbeek, R., McCaughey, M. J. \& Woese, C. R. (1997). The RDP (Ribosomal Database Project). Nucleic Acids Res 25, 109-111.

Messner, P. \& Sleytr, U. B. (1992). Crystalline bacterial cellsurface layers. Adv Microb Physiol 33, 213-275.

Ollivier, B. M., Mah, R. A., Garcia, J. L. \& Boone, D. R. (1986). Isolation and characterization of Methanogenium bourgense sp. nov. Int J Syst Bacteriol 36, 297-301.

Raemakers-Franken, P. C., Voncken, F. G. J., Korteland, J., Keltjens, J. T., van der Drift, C. \& Vogels, G. D. (1989). Structural characterization of tatiopterin, a novel pterin isolated from Methanogenium tationis. Biofactors 2, 117-122.

Rainey, F. A., Ward-Rainey, N., Kroppenstedt, R. M. \& Stackebrandt, E. (1996). The genus Nocardiopsis represents a phylogenetically coherent taxon and a distinct actinomycete lineage: proposal of Nocardiopsaceae fam. nov. Int $J$ Syst Bacteriol 46, 1088-1092.

Rivard, C. J. \& Smith, P. H. (1982). Isolation and characterization of a thermophilic marine methanogenic bacterium, Methanogenium thermophilicum sp. nov. Int J Syst Bacteriol 32, 430-436.

Romesser, J. A., Wolfe, R. S., Mayer, F., Spiess, E. \& WaltherMauruschat, A. (1979). Methanogenium, a genus of marine methanogenic bacteria and characterization of Methanogenium cariaci spec. nov. and Methanogenium marisnigri spec. nov. Arch Microbiol 121, 147-153.

Rouvière, P., Mandelco, L., Winker, S. \& Woese, C. R. (1992). A detailed phylogeny for the Methanomicrobiales. Syst Appl Microbiol 15, 363-371.

Saitou, N. \& Nei, M. (1987). The neighbor-joining method: a new method for reconstructing phylogenetic trees. Mol Biol Evol 4, 406-425.

Sleytr, U. B., Messner, P., Pum, D. \& Sára, M. (1993). Crystalline bacterial cell surface layers. Mol Microbiol 10, 911-916.

Strunk, O. \& Ludwig, W. (1997). ARB software. ftp://ftp.mikro.biologie.tu-muenchen.de/pub/ARB

Tindall, B. J. (1990a). A comparative study of the lipid composition of Halobacterium saccharovorum from various sources. Syst Appl Microbiol 13, 128-130.

Tindall, B. J. (1990b). Lipid composition of Halobacterium lacusprofundi. FEMS Microbiol Lett 66, 199-202.

Widdel, F., Rouvière, P. E. \& Wolfe, R. S. (1988). Classification of secondary alcohol-utilizing methanogens including a new thermophilic isolate. Arch Microbiol 150, 477-481.

Wildgruber, G., Thomm, M., König, H., Ober, K., Ricchiuto, T. \& Stetter, K. O. (1982). Methanoplanus limicola, a plate-shaped methanogen representing a novel family, the Methanoplanaceae. Arch Microbiol 132, 31-36.

Xun, L., Boone, D. R. \& Mah, R. A. (1989). Deoxyribonucleic acid hybridization study of Methanogenium and Methanocorpusculum species, emendation of the genus Methano- 
corpusculum, and transfer of Methanogenium aggregans to the genus Methanocorpusculum as Methanocorpusculum aggregans comb. nov. Int J Syst Bacteriol 39, 109-111.

Zabel, H. P., König, H. \& Winter, J. (1984). Isolation and characterization of a new coccoid methanogen, Methanogenium tatii spec. nov. from a solfataric field on Mount Tatio. Arch Microbiol 137, 308-315.

Zabel, H. P., König, H. \& Winter, J. (1985). Emended description of Methanogenium thermophilicum, Rivard and Smith, and assignment of new isolates to this species. Syst Appl Microbiol 6, $72-78$.

Zellner, G. \& Jargon, A. (1997). Evidence for tungsten-stimulated aldehyde dehydrogenase activity of Desulfovibrio simplex oxidizing aliphatic and aromatic aldehydes with flavins as coenzymes. Arch Microbiol 168, 480-485.

Zellner, G. \& Winter, J. (1987). Secondary alcohols as hydrogen donors for $\mathrm{CO}_{2}$-reduction by methanogens. FEMS Microbiol Lett 44, 323-328.

Zellner, G., Stackebrandt, E., Messner, P., Tindall, B. J., Conway de Macario, E., Kneifel, H., Sleytr, U. B. \& Winter, J. (1989a). Methanocorpusculaceae fam. nov., represented by Methanocorpusculum parvum, Methanocorpusculum sinense spec. nov. and Methanocorpusculum bavaricum spec. nov. Arch Microbiol 151, 381-390.

Zellner, G., Bleicher, K., Braun, E., Kneifel, H., Tindall, B. J., Conway de Macario, E. \& Winter, J. (1989b). Characterization of a new mesophilic, secondary alcohol-utilizing methanogen,
Methanobacterium palustre spec. nov. from a peat bog. Arch Microbiol 151, 1-9.

Zellner, G., Messner, P., Kneifel, H., Tindall, B. J., Winter, J. \& Stackebrandt, E. (1989c). Methanolacinia gen. nov., incorporating Methanomicrobium paynteri as Methanolacinia paynteri comb. nov. J Gen Appl Microbiol 35, 185-202.

Zellner, G., Sleytr, U. B., Messner, P., Kneifel, H. \& Winter, J. (1990). Methanogenium liminatans spec. nov., a new coccoid, mesophilic methanogen able to oxidize secondary alcohols. Arch Microbiol 153, 287-293.

Zellner, G., Geveke, M., Conway de Macario, E. \& Diekmann, H. (1991). Population dynamics of biofilm development during start-up of a butyrate degrading fluidized-bed reactor. Appl Microbiol Biotechnol 36, 404-409.

Zellner, G., Macario, A. J. L. \& Conway de Macario, E. (1997). A study of three anaerobic methanogenic bioreactors reveals that syntrophs are diverse and different from reference organisms. FEMS Microbiol Ecol 22, 295-301.

Zellner, G., Messner, P., Winter, J. \& Stackebrandt, E. (1998). Methanoculleus palmolei sp. nov., an irregularly coccoid methanogen from an anaerobic digester treating wastewater of a palm oil plant in North-Sumatra, Indonesia. Int $J$ Syst Bacteriol 48, 1111-1117.

Zhao, Y., Boone, D. R., Mah, R. A., Boone, J. E. \& Xun, L. (1989). Isolation and characterization of Methanocorpusculum labreanum sp. nov. from the LaBrea tar pits. Int J Syst Bacteriol 39, 10-13. 